\title{
Invasive candidiasis in a Brazilian neonatal intensive care unit
}

Henrique Yuji Watanabe Silva 1

iD https://orcid.org/0000-0001-5379-0980

Felipe Teixeira de Mello Freitas 2

iD https://orcid.org/0000-0001-8894-2614

${ }^{1}$ Hospital Materno Infantil de Brasília. Secretaria de Estado de Saúde do Distrito Federal. Brasília, DF, Brasil.

2 Escola Superior de Ciências da Saúde. Fundação de Ensino e Pesquisa em Ciências da Saúde. SMHN Quadra 03, Conj. A, Bloco 1- Edifício FEPECS. Brasília, DF, Brasil. CEP: 70.710-907. E-mail: felipetmf@gmail.com

\begin{abstract}
Objectives: to describe the epidemiology of invasive candidiasis in a neonatal intensive care unit.

Methods: cross-sectional study that included all neonates with invasive candidiasis confirmed by blood culture from April 2015 to June 2018. Demographic, clinical and microbiological data were analyzed, comparing neonates with extreme low birth weight (ELBW) with neonates $\geq 1000 \mathrm{~g}$ birth weight, considering a $p<0.05$ as statistically significant.

Results: there were 38 cases of invasive candidiasis, resulting in an overall incidence of $2.5 \%$. Twelve (32\%) were ELBW neonates and $26(68 \%)$ neonates $\geq 1000 \mathrm{~g}$ birth weight, an incidence of $4.4 \%$ and $2.0 \%$, respectively. Abdominal surgery was more frequent among neonates with birth weight $\geq 1000 \mathrm{~g}$ compared to ELBW neonates ( $85 \%$ vs. $17 \%$; $p<0.01)$, as well as the median in days of antibiotics use (18 vs. $10.5 ; p=0.04)$. The median in days of mechanical ventilation was more frequent among ELBW neonates (10 vs. $5.5 ; p=0.04)$. The majority of Candida species were non-albicans (64\%). Fatality rate was 32\%.

Conclusions: the incidence of invasive candidiasis among neonates with birth weight $\geq$ $1000 \mathrm{~g}$ was higher than that found in the literature. This group has a higher proportion of gastrointestinal malformations that require surgery. Thus, fluconazole prophylaxis may be necessary for a broader group of neonates.
\end{abstract}

Key words Neonatal sepsis, Candida, Neonatal intensive care unit, Brazil

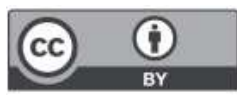




\section{Introduction}

Invasive candidiasis is an important cause of morbidity and mortality among neonates admitted to the Neonatal Intensive Care Unit (NICU). Risk factors associated with invasive candidiasis include prematurity, very low birth weight, vascular catheters, parenteral nutrition, administration of broad-spectrum antibiotics, abdominal surgery, prolonged hospitalization, and artificial ventilation. ${ }^{1-}$ 3 Incidence is especially high among extreme low birth weight (ELBW) neonates (those born with $<1000 \mathrm{~g}$ ), and it has ranged from $2 \%$ to $15 \% .^{2-5}$

Therefore, different strategies have been developed to prevent and improve outcomes related to invasive candidiasis among ELBW neonates. The two main strategies are 1) empiric antifungal therapy, which has reduced Candida associated mortality, 6-8 and 2) fluconazole prophylaxis, which has had an impact in reducing the incidence of invasive candidiasis with no adverse outcomes as fluconazole toxicity or emergence of resistant Candida species. 9,10

Nonetheless, the majority of evidence comes from developed countries; there is scarce data about candida epidemiology in the neonatal population in developing countries, especially from Latin America, where the adoption of fluconazole prophylaxis is not standard practice. Moreover, no attention has been given to candidiasis for neonates with birthweight $\geq 1000 \mathrm{~g}$ with risk factors as abdominal surgery. The reported incidence in neonates with birth weight $>1500 \mathrm{~g}$ is below $1 \% .11$ Therefore, we decided to study invasive candidiasis from a tertiary NICU, a referral center for neonatal surgery and preterm birth, located in Brasilia, Brazil, during a period that fluconazole prophylaxis was not implemented, comparing ELBW neonates and neonates with birthweight $\geq 1000 \mathrm{~g}$, in order to support our decision to begin fluconazole prophylaxis or not.

\section{Methods}

We performed a retrospective, cross-sectional study of all cases of invasive candidiasis identified in our service from April 2015 to June 2018, comparing ELBW neonates with those with birth weight $\geq 1000 \mathrm{~g}$. Our hospital is the largest public maternity hospital in Brasilia, Brazil. It is a regional referral center for preterm-births and neonatal surgery; it has a 30-bed NICU and an intermediate care unit with 16 beds.

We obtained a list of Candida species isolated in blood or cerebral spinal fluid from the microbiology laboratory database and reviewed the patients' records. We collected the following data: gestational age, birthweight, sex, type of delivery, history of abdominal surgery, date of the first positive culture for Candida, platelet count in the occasion of suspected fungal infection, the duration in days of use of mechanical ventilation (MV), central venous catheter (CVC), total parental nutrition (TPN) and antibiotics prior of suspected fungal infection, use of antifungal therapy, duration of hospital stay and patients' outcome: death or hospital discharge.

Neonates with clinical suspicion of infection had their blood samples collected in the volume of $1 \mathrm{~mL}$ and immediately inoculated in bottles for blood culture. Samples were initially submitted to a continuous automated system for microorganism detection (Bactec fluorescent series system ${ }^{\circledR}$ Becton Dickinson Microbiology System). Then, a gram stain was performed and an automated panel of fungal identification (MicroScan Walk-Away ${ }^{\circledR}$ Dade Behring Inc.) was used to identify fungal species.

We analyzed the data descriptively, using proportions for discrete variables and median and inter quartile range (IQR) for continuous variables. We used Chi-square test, or Fisher test when appropriate, for discrete variables and Kruskal-Wallis test for continuous variables to compare ELBW neonates with neonates with birth weight $\geq 1000 \mathrm{~g}$, considering a $p$ value $<0.05$ as statistically significant.

The study was approved by the Ethics and Research Committee of Fundação de Ensino $e$ Pesquisa em Ciências da Saúde - FEPECS (Foundation of Teaching and Research in Health Sciences), CAAE: 81693317.6.0000.5553, under the number 2.514.300.

\section{Results}

During the period of study, there were 1545 admissions in the NICU, 270 (17\%) were ELBW neonates and $1275(83 \%)$ were neonates with birth weight $\geq 1000 \mathrm{~g}$. We identified 38 cases of invasive candidiasis, 12 (32\%) cases among ELBW neonates and 26 (68\%) among neonates with birth weight $\geq 1000 \mathrm{~g}$, resulting in an overall incidence of $2.5 \%, 4.4 \%$ among neonates of ELBW and $2.0 \%$ among those with birth weight $\geq 1000 \mathrm{~g}$.

Considering the 38 cases of invasive candidiasis, the median gestational age was 33 weeks (IQR $28-$ $37)$ and the median birth weight was $1405 \mathrm{~g}$ (IQR $900-2265)$. Nineteen $(50 \%)$ were male, $24(63 \%)$ were born through cesarean delivery and 24 (63\%) had a previous abdominal surgery. The median age during invasive candidiasis onset was 20.5 days old 
(IQR 13 - 37). In seven cases $(18 \%)$, invasive candidiasis was the first episode of late-onset sepsis All cases presented low count of platelets on the day of onset of symptoms and all cases had a previous use of antibiotics; the median duration of antibiotic use was 14.5 days (IQR $9-25$ ). Thirty-one cases $(82 \%)$ had previous use of broad-spectrum antibiotic (ampicillin-sulbactam, piperacilin-tazobactam, cefotaxime, cefepime, meropenem or vancomycin). All cases received TPN; the median duration of TPN use was 17.5 days (IQR 3 - 34). All cases had a CVC, the median duration of CVC use was 19 days (IQR 12 - 36). Thirty-five cases $(92 \%)$ received $M V$ and the median duration of MV was 7.5 days (IQR 4 $20)$. The median duration of NICU stay was 52.5 days (IQR $36-108)$. Three cases ( $8 \%$ ) died before receiving any antifungal therapy, $30(79 \%)$ received antifungal therapy with amphotericin B and 5 (13\%) with fluconazole. There were 12 deaths and a fatality rate of $32 \%$.

Table 1 summarizes the characteristics between neonates of ELBW and those with birth weight $\geq 1000 \mathrm{~g}$. Previous abdominal surgery $(85 \%$ vs. $17 \%$; $p<0.01)$ and days of antibiotic use prior to Candida infection (18vs. $10.5 ; p=0.04)$ were statistically more frequent among neonates $\geq 1000 \mathrm{~g}$ of birth weight. On the other hand, a longer period in days of MV (10 vs. $5.5 ; p=0.04)$ was statistically more frequent among ELBW neonates.

It was not possible to identify the Candida species in $10(26 \%)$ cases. From the 28 remaining samples with species identification, 18 (64\%) were Candida non-albicans, although C. albicans was the main specie isolated (36\%) (Table 2).

\section{Discussion}

Our data shows that invasive candidiasis is a relevant problem in our NICU. Mortality is high, we found a fatality rate of $32 \%$, similar to the $34 \%$ found in a prospective cohort of ELBW neonates, which took place over three years at 19 centers in the United States. ${ }^{1}$ The observed incidence is similar to that reported elsewhere, varying from $0.5 \%$ to $2 \%$ overall and 5\% to $15 \%$ among ELBW.2-5 Data from other Brazilian unit, located in Belo Horizonte, found a higher incidence among ELBW neonates of $9.35 \%$ and $5.25 \%$ when considering the whole cohort of very low birth weight neonates $(<1500 \mathrm{~g})$ during a three-year period, applying different strategies of fluconazole prophylaxis. 12 Nonetheless, our incidence of $2 \%$ among neonates with birth weight $\geq$ $1000 \mathrm{~g}$ is especially high compared to a multicenter study that found an incidence of $0.06 \%$ among neonates with birth weight $>1500 \mathrm{~g} .{ }^{11}$ This may be explained by the high proportion of abdominal surgery seen among neonates with birth weight $\geq 1000 \mathrm{~g}$ with invasive candidiasis in our study. We are a referral center for neonatal surgery and receive a large number of neonates with abdominal malformations and enterocolitis for surgery. Due to abdominal surgery, these neonates are exposed to prolonged time of TPN and broad-spectrum antibiotics, accumulating different risk factors for invasive candidiasis. In fact, gastrointestinal pathologies caused by major malformations were reported as an important risk factor for Candida infections among heavier neonates.11,13,14 Thus, a large number of neonates with invasive candidiasis who underwent abdominal surgery may not receive prophylactic fluconazole, as it is usually prescribed for neonates $<1000$ g. This was already observed in a previous study, which reported that $58 \%$ of neonates with invasive candidiasis did not qualify for fluconazole prophylaxis. 14

Additionally, the exposure to potentially modifiable risk factors, such as use of invasive devices, TPN and antibiotics, was long. Invasive devices, such as CVC may become colonized with Candida and MV may promote colonization of the respiratory and gastrointestinal tract by not allowing normal mucociliary clearance with an endotracheal tube. The use of intralipid emulsions and TPN may have a direct causal effect such as enhancing the growth of fungal pathogens or this may be confounded by delayed enteral feedings. Additionally, it has been shown that the use of broad-spectrum antibiotics may disrupt normal intestinal flora and is associated with invasive candidiasis in different NICUs. 15 This is important because these risk factors may be modified by a clinical care capable to prevent Candida infections.

Candida albicans was the main specie isolated, although the majority of species were non-albicans Candida. As observed in more recent studies, while C. albicans is still the main specie, there is an increasing number of non-albicans Candida causing infections in neonates. 16 Data from 23 units in 8 countries from Latin America, including Brazil, found C. albicans as the main specie (44\%), but nonalbicans Candida predominated (56\%), being $C$. parapsilosis and $C$. glabrata the most isolated, with a low proportion of fluconazole resistant species. 17 It is noteworthy to mention that we isolated only a single fluconazole resistant specie, one case of $C$. glabrata and none of C. krusei. As we did not use fluconazole prophylaxis and our first option to treat Candida infections was amphotericin B, there was 
Table 1

\begin{tabular}{|c|c|c|c|}
\hline \multirow[t]{2}{*}{ Characteristics } & \multicolumn{2}{|c|}{ Birth weight } & \multirow[t]{2}{*}{$p$} \\
\hline & $\begin{array}{c}<1000 g \\
(N=12)\end{array}$ & $\begin{array}{c}\geq 1000 \mathrm{~g} \\
(\mathrm{~N}=26)\end{array}$ & \\
\hline Gestational age in weeks (median, min-max) & $27(24-36)$ & $36(27-39)$ & $<0.01$ \\
\hline Birth weight in grams (median, min-max) & $760(515-990)$ & $1985(1070-3735)$ & $<0.01$ \\
\hline Male sex $(n, \%)$ & $4(33)$ & $15(58)$ & 0.29 \\
\hline Cesarean delivery $(n, \%)$ & $6(50)$ & $18(69)$ & 0.25 \\
\hline Previous abdominal surgery* $(n, \%)$ & $2(17)$ & $22(85)$ & $<0.01$ \\
\hline $\begin{array}{l}\text { Age in days at onset of Candida infection (median, min- } \\
\text { max) }\end{array}$ & $13,5(8-205)$ & $23(7-87)$ & 0.26 \\
\hline $\begin{array}{l}\text { Days of TPN use before onset of Candida infection } \\
\text { (median, min-max) }\end{array}$ & $13(8-53)$ & $20(3-90)$ & 0.21 \\
\hline $\begin{array}{l}\text { Days of CVC use before onset of Candida infection } \\
\text { (median, min-max) }\end{array}$ & $17(7-109)$ & $20(3-85)$ & 0.64 \\
\hline $\begin{array}{l}\text { Days of MV use before onset of Candida infection } \\
\text { (median, min-max) }\end{array}$ & $10(2-103)$ & $5,5(0-39)$ & 0.04 \\
\hline $\begin{array}{l}\text { Days of antibiotic use before onset of Candida infection } \\
\text { (median, min-max) }\end{array}$ & $10,5(4-37)$ & $18(6-78)$ & 0.04 \\
\hline Deaths $(n, \%)$ & $4(33)$ & $8(31)$ & 1.00 \\
\hline
\end{tabular}

ELBW= extreme low-birth weight; TPN= total parenteral nutrition; $C V C=$ central venous catheter; $M V=$ mechanical ventilation.

*There were 8 cases of gastroschisis, 5 intestinal atresia, 3 esophageal atresia, 2 congenital megacolon, 2 gastric perforation, 1 annular pancreas, 1 incarcerated hernia, 1 bowel perforation and 1 anorectal malformation.

no inducible pressure on fluconazole intrinsic resistant Candida strains as it might have had on amphotericin B resistant strains, such as C. lusitaniae and C. guilliermondii. The proportion of $C$. lusitaniae was higher than observed elsewhere; 17 some investigators have theorized that the widespread use of amphotericin B empiric antifungal therapy selects for infections with $C$. lusitaniae and C. guilliermondii. 18

Our study has limitations; this is a relative small retrospective study with no purpose to evaluate risk factors or the effectiveness of prevention measures. Because of laboratory limitations, we were not able to identify Candida species in a quarter of samples. Moreover, the study represents a single unit, with no possible extrapolation for a broader population, especially when it comes to Candida infection that depends of many factors as the proportion of preterm neonates admitted, neonatal surgery and antibiotic prescription practices, among other factors that may differ widely among centers. Nevertheless, its strength is to picture the epidemiology of invasive candidiasis in a highly complex Brazilian NICU before fluconazole prophylaxis, as such strategy is not standard practice in the country. Furthermore, it gives a special attention to heavier neonates that performed abdominal surgery.

In conclusion, after this analysis, we decided to start fluconazole prophylaxis for ELBW because our fatality rate was high and our incidence approached $5 \%$ as it is usually recommended. 19,20 Fluconazole prophylaxis for ELBW has proved to be effective in reducing Candida invasive infection incidence and safe to not provide relevant adverse reaction or development of Candida resistant strains.9,10 Future analytic studies, with a prospective design and groups of comparison, including multiple centers and enough sample are necessary to investigate 


\begin{tabular}{lcc}
\hline List of Candida species isolated in blood culture in a Neonatal Intensive Care Unit, Brasilia, Brazil, $2015-2018$. \\
\hline Candida species & N & $\%$ \\
\hline Candida sp. & 10 & 26.0 \\
Candida albicans & 10 & 26.0 \\
Candida lusitaniae & 6 & 16.0 \\
Candida guilliermondii & 4 & 10.5 \\
Candida parapsilosis & 4 & 10.5 \\
Candida tropicalis & 2 & 5.0 \\
Candida intermedia & 1 & 3.0 \\
Candida glabrata & 1 & 3.0 \\
\end{tabular}

fluconazole prophylaxis for neonates with birth weight $\geq 1000 \mathrm{~g}$ who have gastrointestinal pathologies and undergo abdominal surgery, since this group may consist in a high-risk population for Candida invasive infection in highly complex NICU.

\section{Author's contribution}

Silva HYW and Freitas FTM contributed in the concept of the article and did the data analysis. Silva HYW collected the data and wrote the first draft. Freitas FTM reviewed the first draft and wrote the final version. All authors approved the final version of the article.

\section{References}

1. Saiman L, Ludington E, Pfaller M, Rangel-Frausto S, Wiblin RT, Dawson J, Blumberg HM, Patterson JE, Rinaldi M, Edwards JE, Wenzel RP, Jarvis W; The National Epidemiology of Mycosis Survey study group.Risk factors for candidemia inNeonatal Intensive Care Unit patients. Pediatr Infect Dis J. 2000; 19 (4): 319-24.

2. Benjamin DK Jr, Stoll BJ, Fanaroff AA, McDonald SA, Oh W, Higgins RD, Duara S, Poole K, Laptook A, Goldberg R; National Institute of Child Health and Human Development Neonatal Research Network. Neonatal candidiasis among extremely low birth weight neonates: risk factors, mortality rates, and neurodevelopmental outcomes at 18 to 22 months. Pediatrics. 2006; 117 (1): 84-92.

3. Benjamin DK Jr, Stoll BJ, Gantz MG, Walsh MC, Sánchez PJ, Das A, Shankaran S, Higgins RD, Auten KJ, Miller NA, Walsh TJ, Laptook AR, Carlo WA, Kennedy KA, Finer NN, Duara S, Schibler K, Chapman RL, Van Meurs KP, Frantz ID 3rd, Phelps DL, Poindexter BB, Bell EF, O'Shea TM, Watterberg KL, Goldberg RN; Eunice Kennedy Shriver National Institute of Child Health and Human Development

Neonatal Research Network. Neonatal candidiasis: epidemiology, risk factors, and clinical judgment. Pediatrics. 2010; 126 (4): 865-73.

4. Rodriguez D, Almirante B, Park BJ, Cuenca-Estrella M, Planes AM, Sanchez F, Gene A, Xercavins M, Fontanals D, Rodriguez-Tudela JL, Warnock DW, Pahissa A; Barcelona Candidemia Project Study Group. Candidemia in neonatal intensive care units: Barcelona, Spain. Pediatr Infect Dis J. 2006; 25 (3): 224-9.

5. Xia H, Wu H, Xia S, Zhu X, Chen C, Qiu G, Zhou W, Shi Y, Ma L, Sun J, Zhou X, Zhu J. Invasive Candidiasis in preterm neonates in China: a retrospective study from 11 NICUS during 2009-2011. Pediatr Infect Dis J. 2014; 33 (1): 106-9.

6. Benjamin DK Jr, DeLong ER, Steinbach WJ, Cotton CM, Walsh TJ, Clark RH. Empirical therapy for neonatal candidemia in very low birth weight neonates. Pediatrics. 2003; 112 (3 Pt 1): 543-7.

7. Procianoy RS, Enéas MV, Silveira RC. Empiric guidelines for treatment of Candida infection in high-risk neonates. 
Eur J Pediatr. 2006; 165 (6): 422-3.

8. Greenberg RG, Benjamin DKJ, Gantz MG, Cotten CM, Stoll BJ, Walsh MC, Sánchez PJ, Shankaran S, Das A, Higgins RD, Miller NA, Auten KJ, Walsh TJ, Laptook AR, Carlo WA, Kennedy KA, Finer NN, Duara S, Schibler K, Ehrenkranz RA, Van Meurs KP, Frantz ID 3rd, Phelps DL, Poindexter BB, Bell EF, O'Shea TM, Watterberg KL, Goldberg RN, Smith PB; Eunice Kennedy Shriver National Institute of Child Health and Human Development Neonatal Research Network. Empiric antifungal therapy andoutcomes in extremely low birth weight neonates with invasive candidiasis. J Pediatr. 2012; 161 (2): 264-9.

9. Ericson JE, Kaufman DA, Kicklighter SD, Bhatia J, Testoni D, Gao J, Smith PB, Prather KO, Benjamin DK Jr; Fluconazole Prophylaxis Study Team on behalf of the Best Pharmaceuticals for Children Act-Pediatric Trials Network Steering Committee. Fluconazole Prophylaxis for the Prevention of Candidiasis in Premature Neonates: A Metaanalysis Using Patient-level Data. Clin Infect Dis. 2016; 63 (5): 604-10.

10. Luparia M, Landi F, Mesini A, Militello MA, Galletto P, Farina D, Castagnola E, Manzoni P. Fungal Ecology in a Tertiary Neonatal Intensive Care Unit after 16 Years of Routine Fluconazole Prophylaxis: No Emergence of Native Fluconazole-Resistant Strains. Am J Perinatol. 2019; 36 (S 02): S126-33.

11. Lee JH, Hornik CP, Benjamin DK Jr, Herring AH, Clark RH, Cohen-Wolkowiez M, Smith PB. Risk factors for invasive candidiasis in neonates $>1500 \mathrm{~g}$ birth weight. Pediatr Infect Dis J. 2013; 32 (3): 222-6.

12. Silva-Rios J, Camargos P, Correa L, Romanelli R. Prophylactic regimens with fluconazole for candidiasis in neonates under $1.500 \mathrm{~g}$ : A retrospective chart review of two cohorts. Neonatal Perinatal Med. 2019; 12 (1): 29-36.

13. Rabalais GP, Samiec TD, Bryant KK, Lewis JJ. Invasive candidiasis in neonates weighing more than 2500 grams at birth admitted to a neonatal intensive care unit. Pediatr Infect Dis J. 1996; 15 (4): 348-52.

14. Feja KN, Wu F, Roberts K, Loughrey M, Nesin M, Larson E, Della-Latta P, Haas J, Cimiotti J, Saiman L. Risk factors for candidemia in critically ill neonates: a matched casecontrol study. J Pediatr. 2005; 147 (2): 156-61.
15. Cotten CM, McDonald S, Stoll B, Goldberg RN, Poole K, Benjamin DK Jr; National Institute for Child Health and Human Development Neonatal Research Network. The association of third-generation cephalosporin use and invasive candidiasis in extremely low birth-weight infants. Pediatrics. 2006; 118 (2): 717-22.

16. Steinbach WJ, Roilides E, Berman D, Hoffman JA, Groll AH, Bin-Hussain I, Palazzi DL, Castagnola E, Halasa N, Velegraki A, Dvorak CC, Charkabarti A, Sung L, DanzigerIsakov L, Lachenauer C, Arrieta A, Knapp K, Abzug MJ, Ziebold C, Lehrnbecher T, Klingspor L, Warris A, Leckerman K, Martling T, Walsh TJ, Benjamin DK Jr, Zaoutis TE; International Pediatric Fungal Network. Results from a prospective, international, epidemiologic study of invasive candidiasis in children and neonates. Pediatr Infect Dis J. 2012; 31 (12): 1252-7.

17. Santolaya ME, Alvarado T, Queiroz-Telles F, Colombo AL, Zurita J, Tiraboschi IN, Cortes JA, Thompson L, Guzman M, Sifuentes J, Echevarría JI, Nucci M; Latin American Invasive Mycosis Network. Active surveillance of candidemia in children from Latin America: a key requirement for improving disease outcome. Pediatr Infect Dis J. 2014; 33 (2): e40-4.

18. Krcmery V, Barnes AJ. Non-albicans Candida spp. causing fungaemia: pathogenicity and antifungal resistance. J Hosp Infect. 2002; 50 (4): 243-60.

19. Hope WW, Castagnola E, Groll AH, Roilides E, Akova M, Arendrup MC, Arikan-Akdagli S, Bassetti M, Bille J, Cornely OA, Cuenca-Estrella M, Donnelly JP, Garbino J, Herbrecht R, Jensen HE, Kullberg BJ, Lass-Flörl C, Lortholary O, Meersseman W, Petrikkos G, Richardson MD, Verweij PE, Viscoli C, Ullmann AJ; ESCMID Fungal Infection Study Group. ESCMID* guideline for the diagnosis and management of Candida diseases 2012: prevention and management of invasive infections in neonates and children caused by Candida spp. Clin Microbiol Infect. 2012; 18 (Suppl 7): 38-52.

20. Pappas PG, Kauffman CA, Andes DR, Clancy CJ, Marr KA, Ostrosky-Zeichner L, Reboli AC, Schuster MG, Vazquez JA, Walsh TJ, Zaoutis TE, Sobel JD. Clinical Practice Guideline for the Management of Candidiasis: 2016 Update by the Infectious Diseases Society of America. Clin Infect Dis. 2016; 62 (4): e1-50.

Received on July 27, 2020

Final version presented on December 22, 2020

Approved on February 16, 2021 